\title{
DEMOCRATIZAÇÃO DE LITERATURAS SOB A PERSPECTIVA DA INCLUSÃO
}

\author{
Andreia Marques Melo da Silva ${ }^{1}$
}

\section{Resumo:}

Reinventar-se e buscar novos caminhos frente aos desafios da vida, faz parte da jornada de cada ser humano, no processo do ensinar, orientar e educar não é diferente. Ter o olhar empático e sensível para com todos deve ser um dinamismo que faça parte da nossa atuação em todos os aspectos da nossa prática.

Democratização de literaturas tange a discussão do incluir a respeito de pessoas deficientes no mundo da literatura e no diálogo não como exemplos por suas dificuldades, mas como protagonistas que vivem, crescem, e se descobrem como qualquer ser humano.

Impulsionar a reflexão e a discussão dessa temática é o objetivo desse trabalho.

Palavras chaves: Inclusão, deficiências, educação, literaturas democráticas.

1 Andreia Marques Melo da Silva é formada em Língua Portuguesa e Literaturas, Pedagogia, Psicopedagogia, Neuropsicopedagogia e Educação Especial, Psicanálise, com cursos diversos na área de Transtornos Neurológicos de Aprendizagem, Neuropscicologia e Psicanálise, Escritora na área da inclusão e diversidade, Palestrante, professora de Pós - Graduação, Diretora Mobilizadora em seu município pelo Sindicato dos Psicopedagogos no Brasil, Orientadora na área de inclusão, Atende clinicamente há mais de 7 anos, Mestranda em Educação com viés de pesquisa em Neurociência. 


\section{ABSTRACT}

Reinventing oneself and seeking new paths in the face of life's challenges is part of the journey of every human being, in the process of teaching, guiding and educating is no different. Having an empathetic and sensitive eye towards everyone must be a dynamism that is part of our work in all aspects of our practice.

Democratization of literature concerns the discussion of including people with disabilities in the world of literature and in dialogue not as examples for their difficulties, but as protagonists who live, grow, and discover themselves as any human being.

To stimulate reflection and discussion on this theme is the objective of this work.

Keywords: Inclusion, disabilities, education, democratic literatures.

\section{INTRODUÇÃO}

Ouvimos sobre a importância da leitura, a importância de incentivá-la nos primeiros anos da vida de uma criança e seguir nesse processo por todo o crescimento, o quanto é importante que vejam os pais lendo como exemplo representativo para fortalecer a necessidade e a importância desse ato.

Mas afinal, por que a leitura é tão importante para nós? Para nosso cérebro? O que afinal ela estimula em nós que a faz tão importante para nossas vidas?

Áreas de estudos, como a neurociência, têm proporcionado para nós possibilidades de entendermos como se dá a aprendizagem no nosso cérebro, como novos estímulos que proporcionamos a ele constrói a plasticidade neuronal, trazendo mudanças na área da linguagem, comportamento, nas interpretações que fazemos do mundo.

A alusão a respeito de democratização de literaturas propõe outro lado esquecido pelos educadores, pais, profissionais terapêuticos quanto à reflexão sobre inclusão com aqueles que não são entendidos como pessoas deficientes. 
O quanto falamos a respeito da temática em sala de aula, em consultórios, no âmbito familiar?

A pessoa com deficiência quando tem acesso as literaturas que temos e oferecemos conseguem se encontrar em meio aos personagens como alguém que faz parte da sociedade, não como alguém a margem dela?

Quantos personagens nos livros de contos infantis que oferecemos nas salas de aulas, consultórios e em nossas casas têm autismo, ou dislexia, ou deficiência visual? Como conversamos com nossos filhos, alunos, pacientes/aprendentes com relação a não termos preconceito? Explicamos sobre as deficiências e dificuldades utilizando a nomenclatura da "normalidade" para aqueles que não têm um CID (código internacional de doença)? Pontuamos que todos têm dificuldades? Ou democratizamos a piedade em vez da conscientização de que ser empático é conviver com as diferenças, sobretudo, que começam em nós?

A literatura tem papel primordial nas conexões que fazemos com mundo ao redor, por meio dela entendemos e construímos reflexões, sensações, memórias afetivas, transcendemos como ser humano, este artigo pretende trazer a reflexão a respeito de democratização de literaturas, o quanto ainda precisamos avançar nessa missão, evidenciando por meio da neurociência os benefícios que a mesma agrega em nós que repercutirá em nossa sociedade quanto formação de valores.

\section{NEUROCIÊNCIA E SUAS CONTRIBUIÇÕES}

A neurociência, que debruça a estudar o sistema nervoso, suas ligações com toda a fisiologia do organismo, incluindo, também, a relação entre cérebro e comportamento, funções sensoriais e motoras, memórias de aprendizagem, comunicação e linguagem, tem pontuado o quanto a leitura contribui para ampliação de vocabulário, estímulo de criatividade senso crítico, novas conexões neuronais, entre outros benefícios. 
Stanislas Dehaene, neurocientista francês, em suas pesquisas ressalta a respeito da reciclagem neuronal, muitos neurônios têm a capacidade da plasticidade, ou seja, aprender novas possibilidades que sejam necessárias quando se é estimulado. Em suas falas e escritas pontua que:

[...] as invenções culturais como a leitura se inserem nesta margem de plasticidade. Nosso cérebro se adapta ao ambiente cultural, não absorvendo cegamente tudo o que the é apresentado em circuitos virgens hipotéticos, mas convertendo a outro uso as predisposições cerebrais já presentes. Nosso cérebro não é uma tabula rasa onde se acumulam construções culturais: é um órgão fortemente estruturado que faz o novo com o velho. Para aprender novas competências, reciclamos nossos antigos circuitos cerebrais de primatas (DEHAENE, 2011, p. 20).

Algumas pesquisas realizadas por neurologistas com ressonância magnética em cérebros em momentos de leitura, perceberam que no instante desse processo 0 cérebro faz conexões neuronais relacionadas a vários tipos de memórias, memória de curto prazo, longo prazo, memória episódica, declarativa, semântica, além de raciocínio, percepção, empatia, relacionar situações presentes no texto lido com sua realidade, reflexão.

Segundo Korbinian Brodmann, neurologista e psiquiatra alemão, 1868 -1918, que foi responsável por definir e descrever que o cérebro é organizado em 52 áreas, nosso cérebro está dividido em dois hemisférios cerebrais - direito e esquerdo - que se comunicam entre si, com funções específicas.

A região, no cérebro, responsável pela leitura chama-se occípito-temporal ventral do hemisfério esquerdo, segundo Dehaene ( 2011) quando lemos o cérebro precisa passar por novas ligações sinápticas ( ligações sinápticas diz respeito a comunicação entre os neurônios onde agem os neurotransmissores, mediadores químicos, transmitindo impulsos nervosos), que ocorrem em diferentes regiões. 
Nascemos com ligações sinápticas primárias responsáveis pelas atividades básicas como respirar, enxergar, se alimentar, entretanto para desenvolvermos outras áreas, secundárias e terciárias no cérebro, de aprendizagens é preciso, primeiro, haver a maturação das células e o estímulo de aprendizagem para novas conexões, que possibilitam a reação biológica em conexão com os estímulos culturais que somos apresentados e vivenciamos.

Entre outras colaborações que Dehaene ( 2011) traz com relação ao estudos de neurociência e leitura, é pontuar onde ocorre o processamento da decodificação leitura no cérebro, mais de onze áreas são estimuladas no cérebro em momento de leitura, algumas delas, por exemplo, são responsáveis pela pronuncia e articulação, em dar sentido ao que se lê, memórias, entre outras.

\section{DEMOCRATIZAÇÃO DE LITERATURAS E O COMPROMISSO SOCIAL DA INCLUSÃO}

A neurociência tem contribuído de forma efetiva e assertiva para compreendermos como o processo de aprendizagem acontece em nosso cérebro e as invocações quanto aos reflexos dessas aprendizagens em nosso comportamento relacionado com nosso cotidiano integrado a sociedade da qual fazemos parte.

A partir dessas prerrogativas, entendemos que quanto mais estimulamos nosso cérebro, mais conexões neuronais acontecem, mais ampliamos nossa forma de ler e entender o mundo, mais nos colocamos no lugar do outro - EMPATIA -, mais entendemos o mundo por outras perceptivas e interpretações.

A democratização de literaturas trata, justamente, do termo empatia, da reflexão sobre comportamento, das possibilidades diferentes de ler o mundo, muitas vezes, maneiras essas arraigadas pela falta de informações, ou informações alicerçadas em preconceito. 
Democratizar é propiciar vertentes reflexivas dentro das literaturas narrativas de todas as faixas etárias com a presença de protagonistas, antagonistas, coadjuvantes personagens que fazem parte do nosso dia a dia, que tenham dificuldades acentuadas, deficiências, transtornos, síndromes, todavia não deixam de viver, de superar suas dificuldades, de estarem na vida e no dia a dia de todos nós, diante disso alemos a interrogativa da suspensão em nossas reflexões e literaturas de assuntos como esses.

Ninguém nasce feito, ninguém nasce marcado para ser isso ou aquilo. Pelo contrário, nos tornamos isso ou aquilo. Somos programados, mas, para aprender. A nossa inteligência se inventa e se promove no exercício social de nosso corpo consciente. Se constrói. Não é um dado que, em nós, seja um a priori da nossa história individual e social." - Paulo Freire Política e educação: ensaios - Pg.104,

Quando um sujeito tem acesso somente a livros, informações, diálogos, em que os protagonistas pertencem apenas a um tipo de classe social, biótipo, como se houvesse um mundo paralelo, entende-se que não se oferece a ele a possibilidade de ampliar conhecimento de outros mundos, acessar outras culturas, o diverso existente em nossa realidade.

\section{PRÁTICAS DE APRENDIZAGEM ALICERÇADAS EM DEMOCRATIZAÇÃO DE LITERATURAS}

Quem lida com a realidade do diverso desde pequenino não terá estranheza diante de uma rampa de acessibilidade, de um colega autista que precisa sair para dar uma caminhada pela escola mais vezes do que ele, de uma colega que precisa ter uma prova impressa em fonte 14 porque tem dislexia e que ler textos longos, para mesma, é difícil, algo que não é para uma criança que não tem o transtorno de leitura e escrita - dislexia. 
Ter contato com diverso permite que se perceba que o "eu" faz parte desse diverso não por ser perfeito, mas por ter também suas limitações sendo elas amplas ou não, que esse universo não é paralelo ao meu porque eu estou nele tanto quanto uma pessoa deficiente visual ou com TDAH, por exemplo.

A BNCC - Base Nacional Comum Curricular - documento normativo para todas as redes de ensino e suas instituições públicas ou privadas, sendo uma referência obrigatória de elaboração dos currículos escolar, prevê em suas competências gerais no nono parágrafo:

9- Exercitar a empatia, o diálogo, a resolução de conflitos e a cooperação, fazendo-se respeitar e promovendo o respeito ao outro e aos direitos humanos, com acolhimento e valorização da diversidade de indivíduos e de grupos sociais, seus saberes, identidades, culturas e potencialidades, sem preconceitos de qualquer natureza. (COMPETÊNCIAS GERAIS DA EDUCAÇÃO BÁSICA BNCC - Base Nacional Comum Curricular -2018).

Ressignificar a prática da produção textual, das narrativas, das reflexões, das conversas, das brincadeiras em sala de aula, em consultório, no âmbito familiar em momentos de conversas é um convite para se repensar como lidamos verdadeiramente com a ideia da inclusão. Dar acesso à sala de aula para uma pessoa deficiente não necessariamente é democratizar aprendizagem, sabemos e discutimos os avanços e retrocessos, ainda, no século XXI na área da educação inclusiva, mas se deixa de lado a orientação, a quebra de paradigmas construídos sobre preconceitos, não se olha para o estudante sem laudo e o convida a refletir sobre suas dificuldades e sobre o olhar empático, e o porquê de tê-lo, sem preconceito para com o colega ao lado.

Paulo Freire (1988) nos sinala em seus textos que a leitura do mundo precede a leitura da palavra, ou seja, as conexões memoráveis vêm à tona em nossa formação quanto ser humano, antes mesmo das palavras, portanto, a leitura é mais um meio de 
estimular e consolidar a ampliação de interpretação de possibilidades que oferecemos aos nossos filhos, alunos e pacientes.

Lev Vygotsky, psicólogo (1896-1934) que morreu há mais de 70, deixou-nos estudos de grande prevalência muito utilizados na área da educação, discorreu em suas obras sobre a compreensão do homem que se forma em contato com a sociedade e o arredor, em uma formação dialética, ou seja, o homem modifica o meio e o meio modifica o homem, em que bem resume Vygotsky, "Na ausência do outro, o homem não se constrói homem".

\section{CONCLUSÃO}

Não é possível haver conscientização significativa enquanto à inclusão e pessoas com deficiências forem apenas lembradas para exemplificar a temática sobre o assunto, não é possível demolirmos as barreiras do preconceito se nos enxergarmos sempre na perspectiva da normalidade e sendo assim, vivermos em um mundo a parte em nossas possibilidades de manifestações por meia da arte, reflexões e literaturas, na tentativa humana quanto à ressignificar o sentido da vida, sem democratizarmos a participação efetiva de todos nesses segmentos.

Enquanto não repesarmos sobre as temáticas que trazemos ou adaptamos em manifestações de escritas, reflexões, entre outras, nos âmbitos de aprendizagens e nos lares, inclusão será um assunto restringido, quanto mais falarmos a respeito de inclusão menos teremos que desmistificar ideias impostas e conversarmos sobre preconceito, mais poderemos falar em novas ações, ampliações em maneiras de ler o mundo e entendermos extensivamente o outro, para se consolidar o processo de civilidade verdadeira entre nós. 


\section{REFERÊNCIAS BIBLIOGRÁFICAS}

$\underline{\text { basenacionalcomum.mec.gov.br/images/BNCC El EF } 110518 \text { versaofinal sit }}$

DEHAENE, STANISLAS - Os neurônios da leitura - 2011 - Editora Penso

FREIRE, PAULO Política e educação: ensaios - Página 104, Paulo Freire - Cortez Editora, 1993, 119 páginas.

Jornal.usp.br/atualidades/telencefalo-e-a-principal-divisao-do-cerebro/

MACHADO, ANGELA - Neuroanatomia funcional - Editora Atheneu - 2013

periodicos.ufsc.br/index.php/workingpapers/article/view/

VIGOTSKI, L. S. Pensamento e Linguagem. Trad. Jefferson Luiz Camargo. 2 ed. São Paulo: Martins Fontes, 1999

www.Kenhub. com/ pt/dashboard

www.scielo.org 